\title{
THE HEART IN THYROID DISEASE. I. THE EFFECT OF THYROIDECTOMY ON THE ORTHODIAGRAM ${ }^{1}$
}

\author{
By ALEXANDER MARGOLIES, EDWARD ROSE AND FRANCIS C. WOOD \\ (From the Robinette Foundation and the Thyroid Clinic, Hospital of the University of Pennsylvania, Philadelphia)
}

(Received for publication March 28, 1935)

The observations which we wish to report have been made with two purposes in mind: to determine (1) what changes, if any, occur in the size and shape of the heart, as determined by orthodiagraphy, in patients with toxic and non-toxic goiter, and (2) the effect of partial or subtotal thyroidectomy, in the same subjects, upon the orthodiagram. Our material consisted of $102 \mathrm{pa}-$ tients with toxic goiters, and 35 with non-toxic goiters. The non-toxic group consisted of the nodular variety except for one case of carcinoma; several patients had diffuse enlargements of the gland in association with the non-toxic nodules. In a few instances the presence of hyperthyroidism was not easy to determine. Such cases were classified only after consideration and correlation of the history, physical findings, basal metabolism readings, and histologic appearance of the excised thyroid tissue. All patients were on the Thyroid Surgical Service of Dr. C. H. Frazier at the Hospital of the University of Pennsylvania and were studied through his courtesy. The operation consisted of subtotal thyroidectomy in 84 of the toxic patients (performed in one stage in 51 cases and in two stages or more in 33) and unilateral lobectomy in the remaining 18 (16 nodular and 2 diffuse). In the non-toxic group unilateral lobectomy was done in 23 , and subtotal thyroidectomy in 12 . The anesthesia in almost all instances was a combination of nitrous oxide and local, often with pre-anesthetic narcosis obtained by avertin.

The plan of study included-in addition to the usual history, physical examination, and routine blood and urine studies-electrocardiograms, orthodiagrams, and basal metabolism determinations made as soon as possible after admission to the Ward. ${ }^{2}$ The latter three studies were repeated

${ }^{1}$ Read in Abstract before the Section on General Medicine, College of Physicians of Philadelphia, April 23, 1934.

2 A number of patients were examined in the Outpatient Clinic before admission to the Ward, and these studies were included in the analysis. within 7 days after operation and at intervals of about 3, 7, and 12 months thereafter. All three studies were usually made on the same day; when this was not possible, the interval between them did not exceed 3 days. In those patients of the toxic group who had multiple stage operations, follow-up intervals were dated from the last operation. Additional clinical studies were made when indicated. Thirty patients were followed for less than one year. Four toxic patients have been followed for over 2 years. Observations on the general physical condition with particular respect to the cardiovascular system and thyroid were made at each follow-up examination. All orthodiagrams were made by the same individual (A. M.).

\section{HEART SIZE}

The literature concerning heart size in patients with goiter presents certain difficulties when attempts at comparison are made because of (1) varying classifications of thyroid disease; (2) different methods employed in measuring the heart and determining significant variations from normal in size; and (3) the inclusion of patients with associated conditions which might, per se, affect the size and shape of the heart.

Table I presents a review of the literature on heart size in goiter before and after thyroidectomy. Considering only those authors who classify their cases as toxic and non-toxic, it will be seen that the preoperative percentage of cases with cardiac enlargement varies from 26 to 83 per cent in the toxic cases and from 10 to 59 per cent in the non-toxic cases. Exclusion of groups with associated cardiovascular disease reduces the percentages in the toxic group to the range 26 to 32 per cent and in the non-toxic group to the range 10 to 14 per cent. The analysis of postoperative changes in heart size in the few satisfactory reports indicates that there is a tendency for hearts enlarged before operation to become smaller or remain unchanged in size, whether associated with toxic or non-toxic goiter. 
TABLE I

Summary of literature on heart size in patients with goiter before and after thyroidectomy

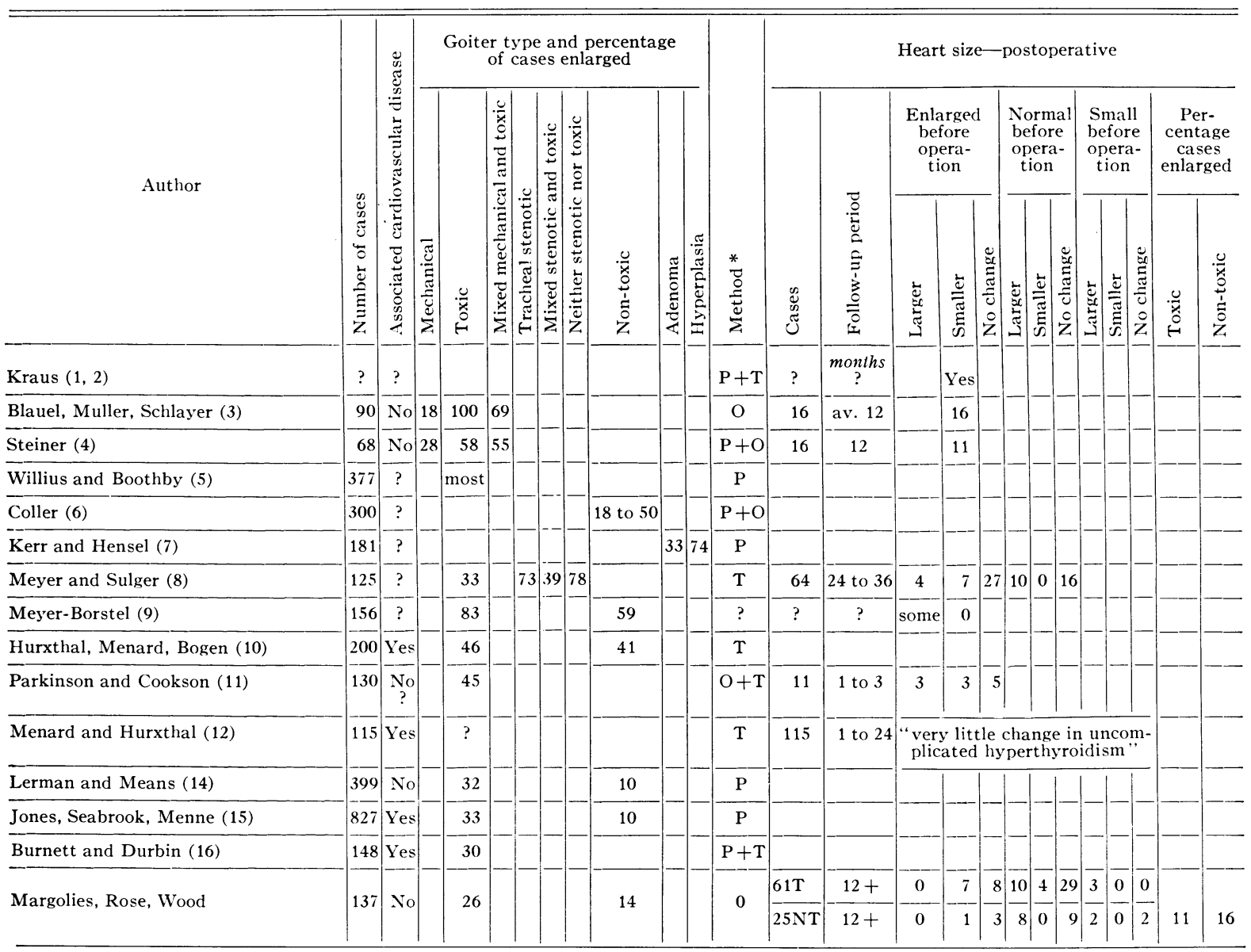

* Method used to determine heart size, P, percussion; T, teleoroentgenograms; O, orthodiagrams.

Postmortem studies on thyrotoxic patients confirm the presence of cardiac hypertrophy in 50 to 75 per cent of cases $(5,11,17)$. (Many of these patients, however, had associated cardiovascular disease.) Furthermore, thyroid feeding in dogs causes cardiac hypertrophy, which involves all chambers of the heart with slightly greater proportional increase in the left ventricle (18).

\section{METHOD}

We employed the orthodiagraphic method to record the contours of the heart. In our opinion this method, when carefully performed, is more reliable and accurate than percussion and teleoroentgenography. The patients were examined in the erect posture, in the four standard posi- tions. ${ }^{3} \quad$ The diaphragm and heart borders were drawn at the end of normal inspiration. Cardiac size was determined by measuring the frontal area, transverse diameter and the anteroposterior diameter. To obtain the frontal area it is necessary to complete arbitrarily the upper and lower borders of the heart by continuing the curves of the right and left borders toward the midline (Figure 1). No attempt was made to obtain the systolic and diastolic size of the heart for two reasons: (1) the difficulty of doing this in a rapidly beating heart, and (2) the difference in frontal area in the two phases of the heart beat

3 Anteroposterior position, right anterior oblique position at 45 degrees, left anterior oblique position at 45 degrees and the left lateral position. 

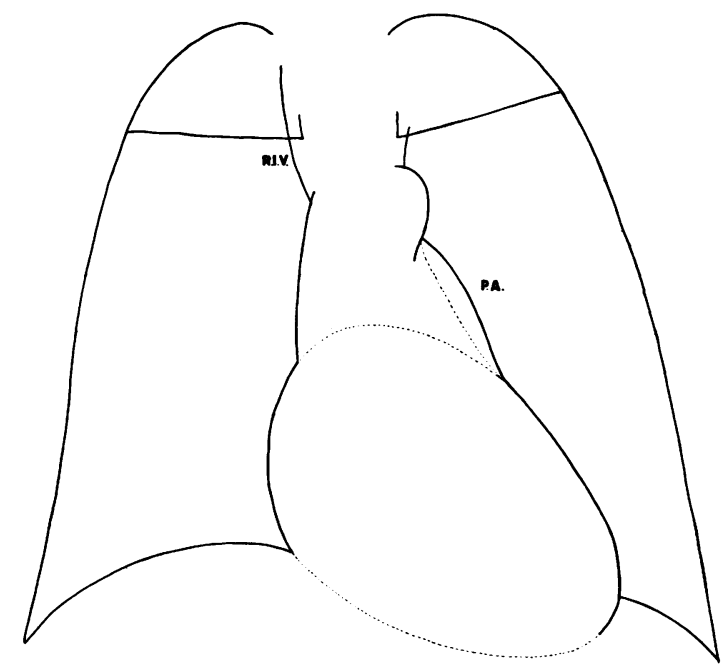

Fig. 1. Typical Orthodiagram in Hyperthyroidism, Showing Increased Prominence of Pulmonary Artery (P. A.).

The broken line indicates the position of the border of the pulmonary artery after relief of hyperthyroidism. The curved broken lines show the method of arbitrarily completing the upper and lower borders of the heart to obtain the frontal area. (See text).

would fall within the limits of error of the method and within the range of normal variation.

\section{Relative heart size}

Simple empiric observation of the relative sizes of the heart and thoracic cage has been superseded to a considerable extent by more exact measurements (19). Diagonal measurements are unreliable, in our experience, because of their variability with cardiac position and their wide normal range. Determination of cardio-thoracic ratio in a series of normals has convinced us that the range of normal variation is too wide to be of value in the determination of cardiac enlargement in the individual case. The position of the heart in the chest and the cross-sectional shape of the chest are so variable normally that attempts to relate heart size to chest measurements are subject to error. This criticism applies also to attempts to measure differential enlargements of the ventricles by the median right and median left diameters. Many normal hearts occupy a central or a left lateral position without respect to a more or less transverse position. No reliable method has yet been devised to determine roentgeno- graphically the relative contributions of the right and left ventricles in an enlarged heart (20). Alterations in shape may, however, suggest preponderance of one or the other ventricle. Determination of the size and shape of the heart shadow does not, of course, give any information as to whether increase in size is due to true hypertrophy, dilatation of the chambers, or to both.

It seems more reasonable to relate heart size to body size in the individual. Theoretically, the ideal would be the heart-volume, body-size ratio, but in the absence of criteria for that correlation we placed greatest reliance on the frontal area and transverse diameter in relation to height and weight, and made use of the tables of Hodges and Eyster $(21,22)$. The heart size was considered within normal limits when the area was not more than 15 per cent above or below the predicted normal for height and weight, ${ }^{4}$ and the transverse diameter less than $1.5 \mathrm{~cm}$. from the prediction. All graphs and tables, however, refer to area alone. The anteroposterior diameter of the heart was used to determine the normality of heart depth. We believe that if a sufficiently wide range of normal variation is allowed, cardiac area may be accepted as a reliable index of heart size in patients whose anteroposterior cardiac diameter falls within the average normal range (23). Two patients were excluded from our analysis because their hearts presented a definitely enlarged frontal area, but with anteroposterior diameters much below the average normal range due to compression in a shallow chest.

The heart size was considered to have changed significantly when the variation in area was 10 per cent or more of the measurement with which it was compared. This standard was adopted so as to include the maximum possible technical error and the change in predicted heart size due to change in weight. ${ }^{5}$

Our analysis of changes in the orthodiagram as shown in the accompanying figures has included only those patients without associated conditions

\footnotetext{
4 Normal hearts are rarely found to be more than 15 per cent above the predicted area.

5 From the tables of Hodges and Eyster $(21,22)$ it was computed that the cardiac area should vary 3 per cent for each 20 pounds change in weight, height remaining the same.
} 


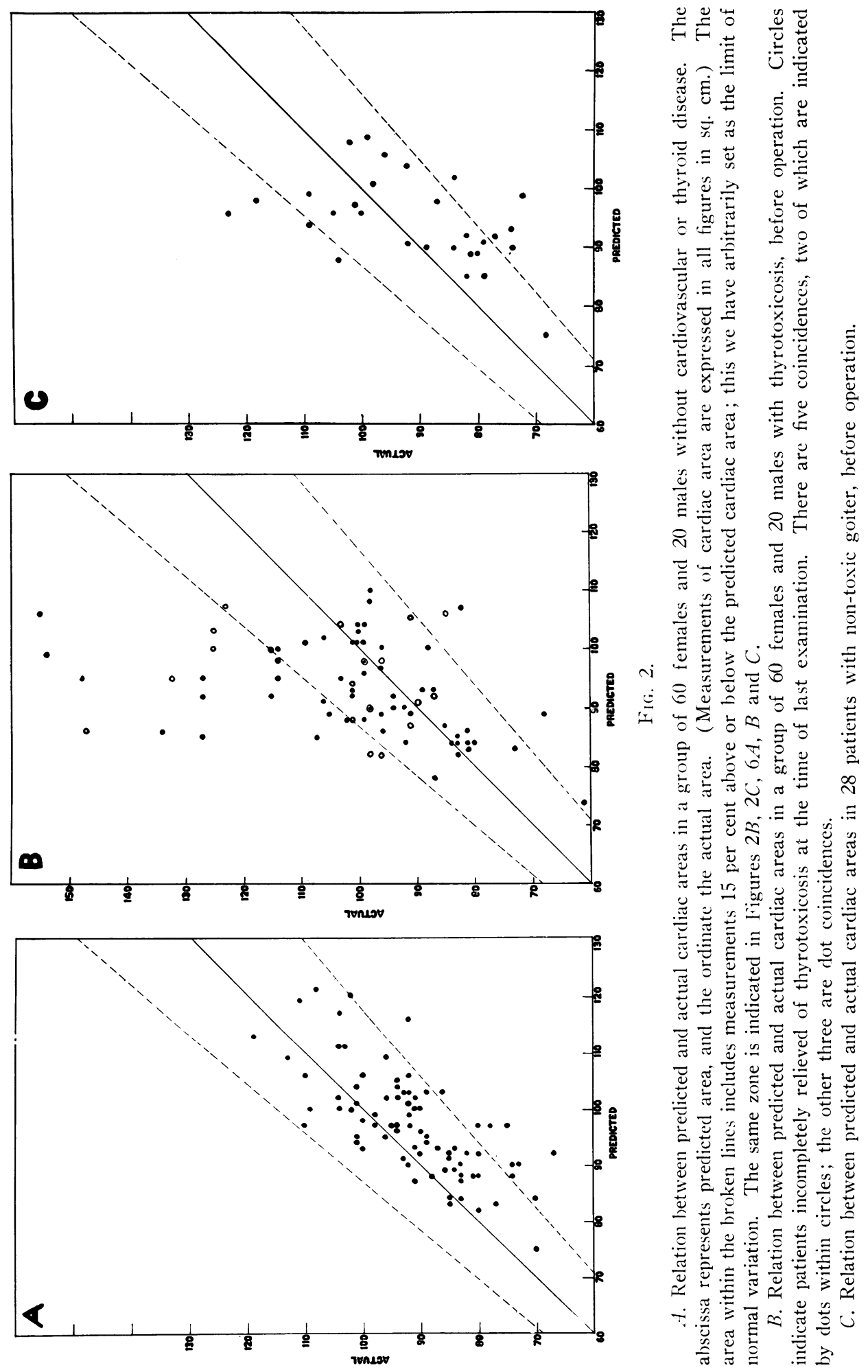


(particularly cardiovascular lesions) which might affect the size and shape of the heart. This has resulted in the exclusion of 21 of the toxic group and 7 of the non-toxic group. Two patients with persistent auricular fibrillation, but without signs of failure, were included (Figure 5, A. F.).

Figure $2 A$ shows the relation between the actual and predicted cardiac areas in a group of 60 females and 20 males without cardiovascular or thyroid disease. The ages of the females ranged from 14 to 61 years, with an average of 34.8 years; the ages of the males ranged from 14 to 60 years, with an average of 38.9 years.

Figure $2 B$ shows the same relation between actual and predicted area in a group of 60 females and 20 males with thyrotoxicosis. The females varied in age from 14 to 61 years, with an average of 36.7 years; the males varied in age from 13 to 59 , with an average of 35.6 years. Twentysix per cent of the thyrotoxic group had enlarged hearts, and 5 per cent had small hearts. In the control group (Figure $2 A$ ) cardiac enlargement was present in none, and 12.5 per cent had small hearts.

Fourteen per cent of 28 patients with non-toxic goiter showed enlarged hearts, and 18 per cent small hearts (Figure 2C). Twenty-seven of this group were females, ranging in age from 14 to 61 years, with an average age of 39 . The one male was 44 years old.

Figure 3 shows individual variations in cardiac area throughout the period of observation in the 28 patients with non-toxic goiters. Twenty-five of these patients were followed for one year or more after operation. Examination of this figure shows that cardiac enlargement was present before operation in 4 cases ( 14 per cent); 3 of these showed no significant change in size after operation; one became smaller. Increase in cardiac area after operation occurred in 11 (39 per cent); 8 were normal in size and 3 were small before operation. Sixteen ( 57 per cent) showed no significant ultimate change. Of the 5 hearts classified as small before operation, 3 increased in size postoperatively and 2 were unchanged.

Figures 4 and 5 represent similar individual variations in 80 thyrotoxic patients (one case is not recorded because of insufficient follow-up data). Sixty-one of these patients were followed

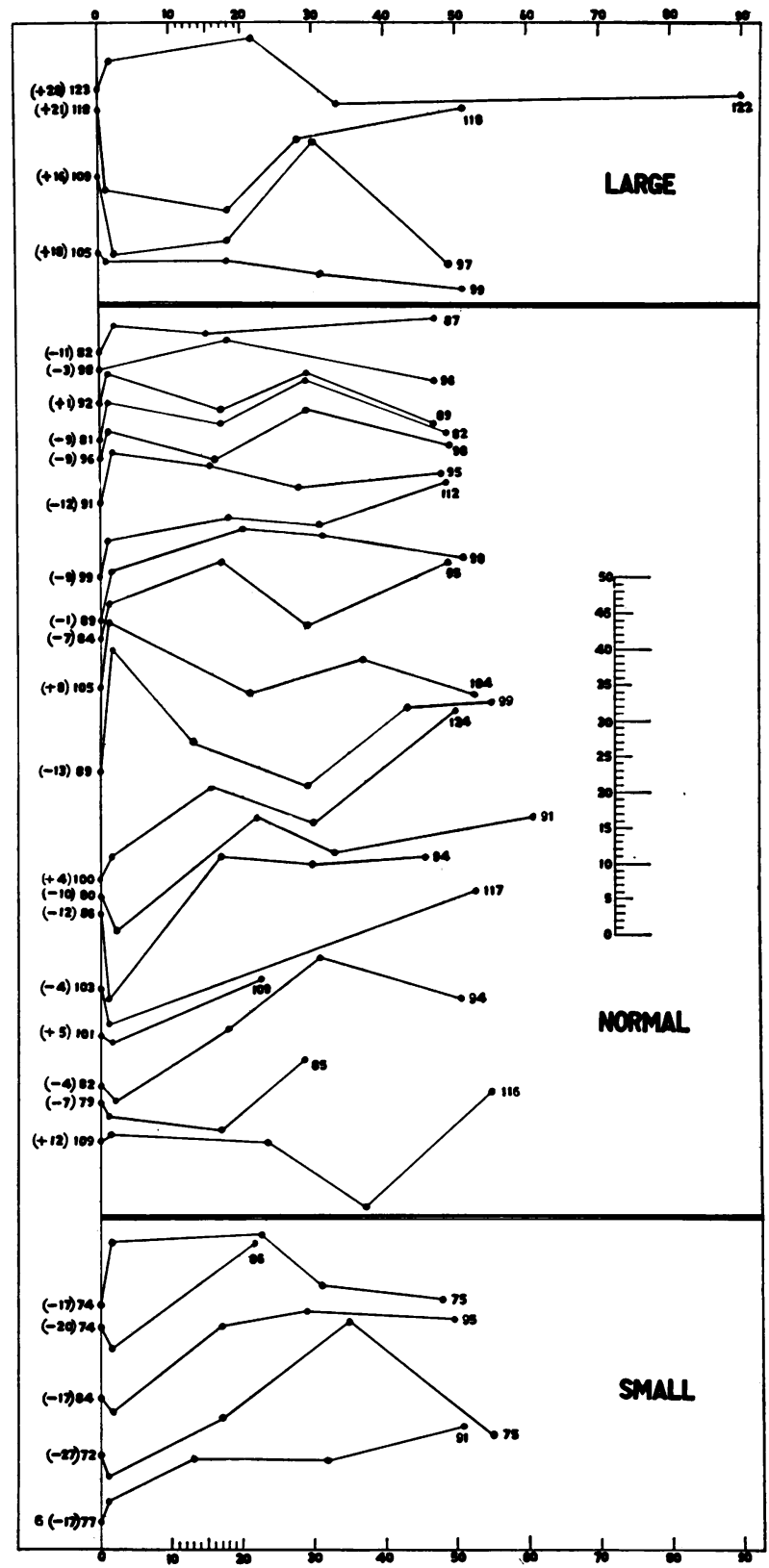

Fig. 3. Individual Variations in Cardiac Area Throughout the Period of Observation in 28 PaTIENTS With Non-Toxic Goiter.

Thyroidectomy was done in all cases between the first and second measurements. Abscissa represents weeks of observation. The percentage relation to predicted area is expressed by the figures in parentheses in the column on the left; other figures represent actual cardiac area before operation and at the last examination after operation. $\mathrm{G}=$ patient growing throughout the period of observation. The scale (in sq. $\mathrm{cm}$.) may be used to determine variations in area between any two measurements on the same curve. Cases in Figures 3, 4 and 5 are grouped according to heart size before operation. 


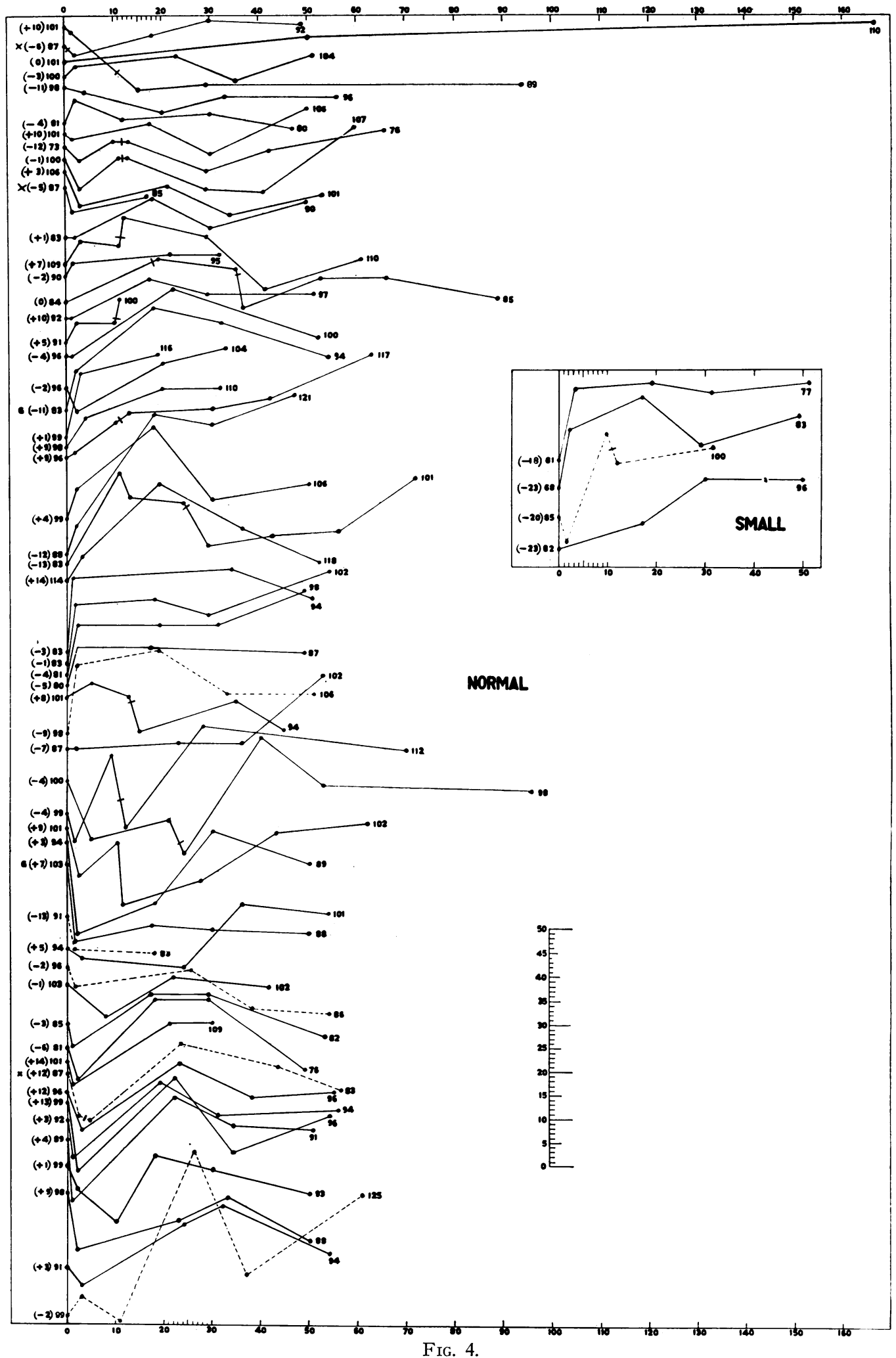

See Figure 5 for legend. 


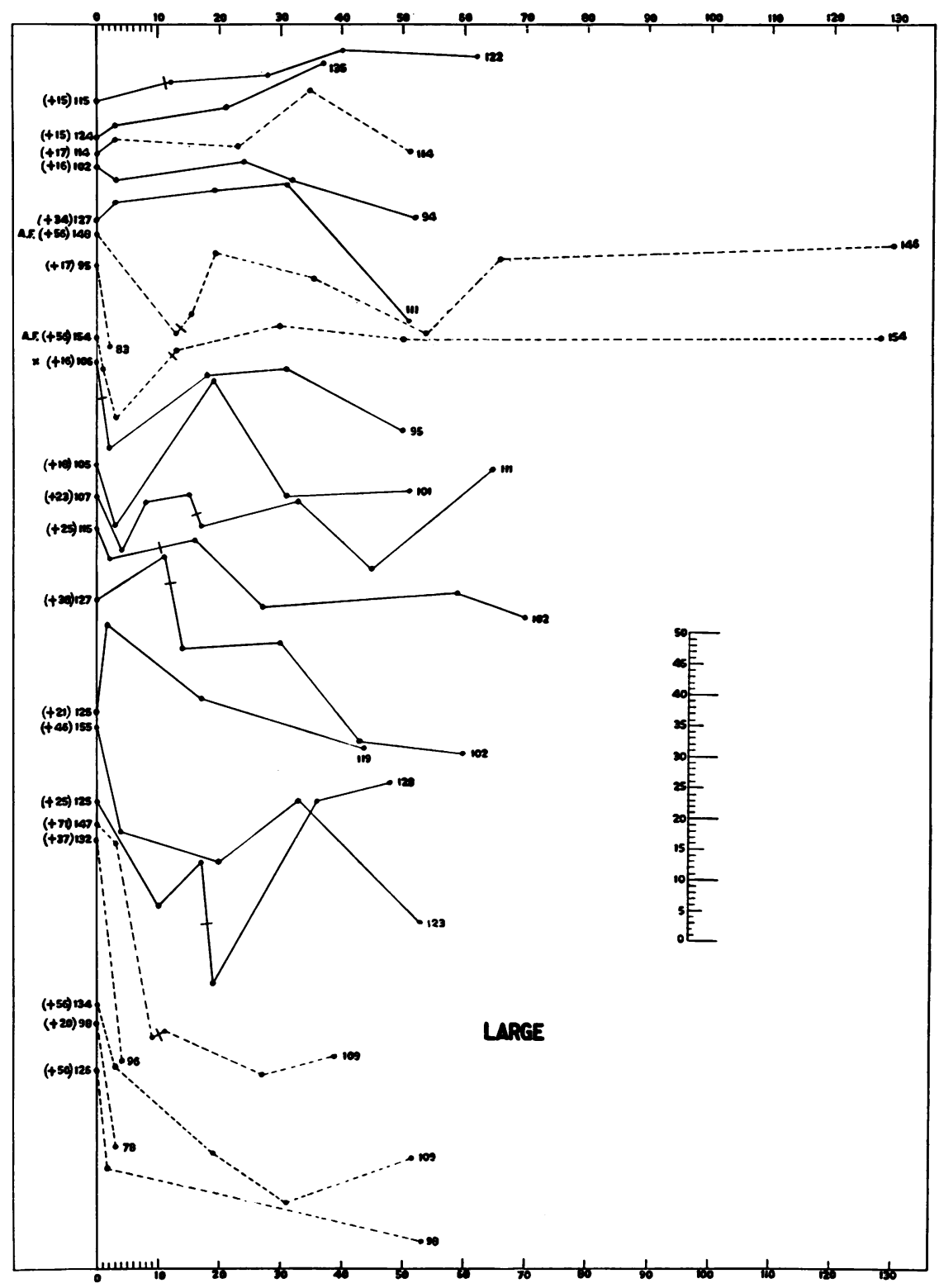

FIG. 5.

Figs. 4 and 5. Individual Variations in Cardiac Area Throughout the Period of Observation in 80 Patients with Thyrotoxicosis.

Thyroidectomy was done between the first and second measurements in all cases except those marked with an $\mathrm{x}$ ( 4 cases), in which operation was done before the first measurements. The short perpendicular cross lines indicate the time of a second operation, usually a hemi-thyroidectomy. The eleventh curve from the top (Figure 4 ) is that of a patient who had only one operation, and in whom cardiac measurements were first recorded 3 days postoperatively. The cases incompletely relieved of thyrotoxicosis are indicated by broken lines. $\mathrm{AF}=$ auricular fibrillation. $\mathrm{G}=$ patient growing during observation. 
for one year or more after operation: of these, 52 were completely relieved of their thyrotoxicosis at the time of the last examination, and 9 showed evidence of incomplete relief. Preoperative cardiac enlargement was almost twice as frequent ( 21 cases or 26 per cent) as in the nontoxic group. Significant ultimate changes in size occurred in 31 (39 per cent). None of the enlarged hearts showed further increase in size, and 11 showed reduction, including 6 in patients who were incompletely relieved of their thyrotoxicosis. All of the 4 small hearts became larger after operation. Of the 55 patients with hearts of normal size before operation, 12 increased significantly in size after operation, 39 remained unchanged, and 4 became smaller. Cases presented in Figures 3, 4 and 5 which were followed for one year or more are included in Table I.

The frequency with which cardiac enlargement occurred in our cases of uncomplicated thyrotoxicosis seems to be significant. The number of cases of non-toxic goiter studied was not large enough to warrant any definite conclusions regarding the incidence of cardiac enlargement, but its frequency was greater than normal. The average degree of enlargement (expressed in terms of percentage increase above the predicted area) in the toxic group (21 cases) was 32 per cent, and in the non-toxic group ( 4 cases) 21 per cent. Of the 21 thyrotoxic patients with enlarged hearts, 19 had diffuse goiters, and 2 nodular goiters.

Of 53 patients in the thyrotoxic group, eleven per cent showed enlargement one year or more after successful thyroidectomy; the remainder were within the normal zone (Figure $6 A$; cf. Figure $2 B$ ).

Of 12 thyrotoxic patients who were incom- pletely relieved, nine were followed for one year or more, and one each for 20,30 and 40 weeks respectively. Six showed change in actual area of less than 10 per cent, 4 had decreased 10 per cent or more, and only 2 showed increase in size (Figure $6 B$ ).

Figure $6 C$ shows the relation between actual and predicted areas in 25 patients with non-toxic goiter one year or more after operation. Comparison of the relative proportion of large, small and normal hearts in 25 patients with non-toxic goiter before and one year after operation shows no significant shift (Figure 2C, cf. Figure 6C).

We were unable to demonstrate any significant relation between the duration of thyrotoxicosis or of non-toxic goiter, as determined roughly from the history, and the incidence of cardiac enlargement. In the thyrotoxic patients without heart failure some of the most marked cardiac enlargements occurred in cases of apparently short duration. Because of the marked tendency to spontaneous fluctuation in the intensity of thyrotoxicosis, we made no attempt to correlate this factor with abnormalities of heart size.

The relation between changes in body weight and cardiac area during the period of observation is shown in Table II. Without significant weight change, the non-toxic patients showed a greater tendency to significant increase in heart size than did the toxic group with cardiac compensation preserved. The latter showed a more marked tendency to gain weight after operation, as might have been anticipated. Actual variations in cardiac area bore no direct relation to changes in predicted area based on weight changes. There clid, however, seem to be a tendency toward increase in heart size with increasing gain of weight (compare columns $A$ in Table II).

TABLE II

The relation betacen changes in body a'elyht and cardiac area

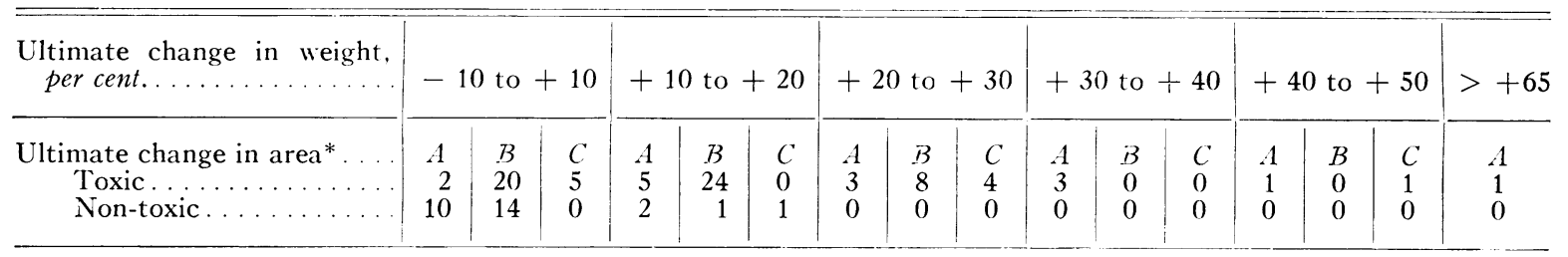

* A-Ultimate increase in area of 10 per cent or more. $B$-Ultimate change in area of less than 10 per cent. $C$-Ultimate decrease in area of 10 per cent or more. 


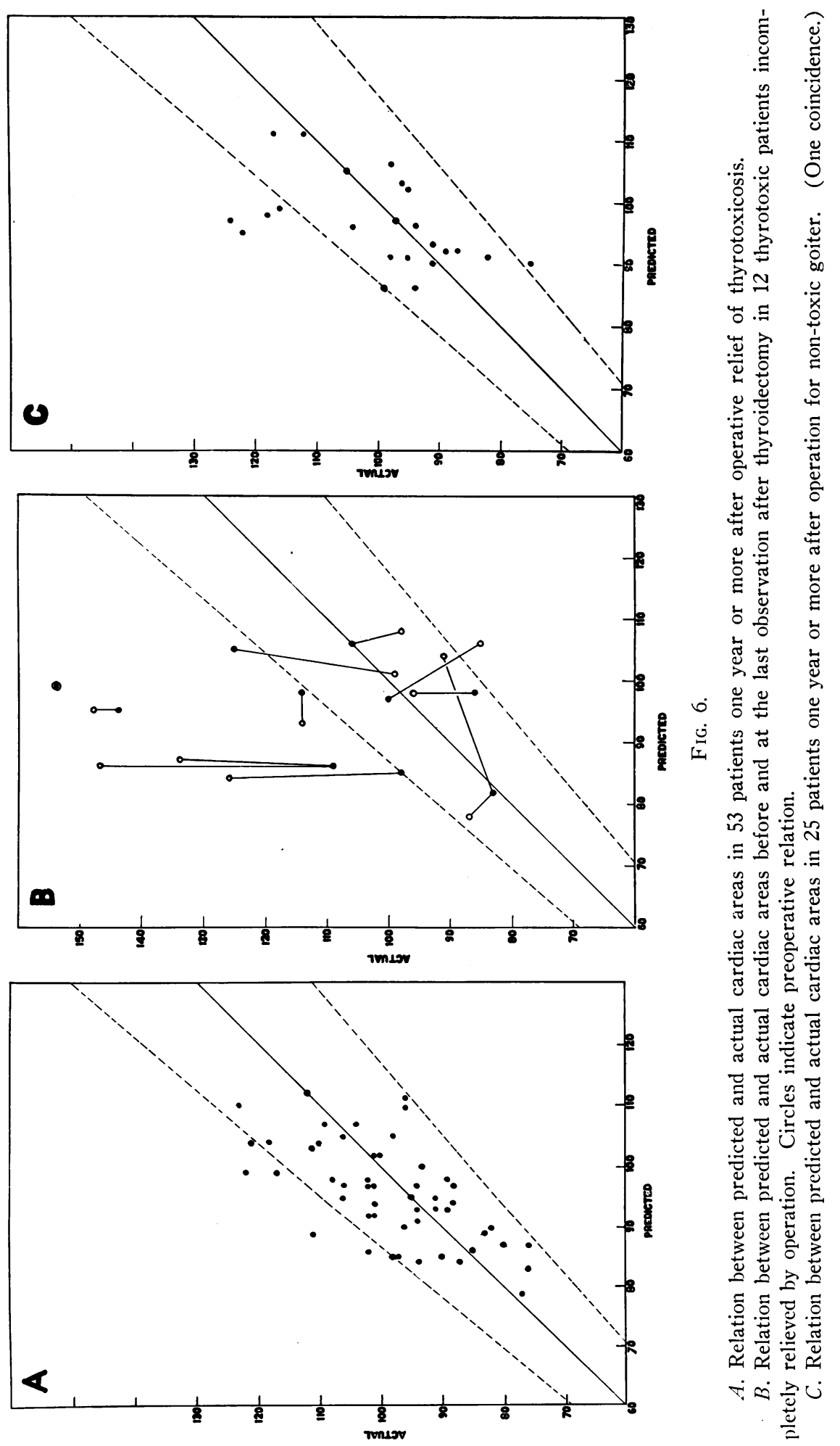


Nine toxic patients showed either a reduction of the basal metabolic rate to -15 per cent or below, or exhibited other evidence of hypothyroidism after operation. In 5 these changes were not associated with any significant variation in cardiac area. In 4 there was an increase in heart size varying from 9 to 18 per cent up to the time of appearance of the thyreoprival signs. In 3 of these patients there was coincidental weight gain. In 3 non-toxic patients the basal metabolic rate dropped after operation to -15 per cent or below, and in 2 others mild thyreoprival symptoms appeared. In the latter two no change in cardiac area occurred. Of the former, 2 showed increase in cardiac area of 11 and 12 per cent respectively without significant weight gain. It appears that postoperative hypothyroidism may be partly responsible for increase in cardiac area occurring after thyroidectomy (13).

Sex did not seem to influence the incidence of cardiac enlargement in the toxic group. All but one of the non-toxic patients were females.

Table III shows the age distribution with refer-ence to the incidence of cardiac enlargement. The

TABLE III

The relation between age and the incidence of cardiac cnlargement (15 per cent or more above prediction)

\begin{tabular}{l|c|c|c|c}
\hline \hline \multirow{2}{*}{ Decade } & \multicolumn{2}{|c|}{ Toxic } & \multicolumn{2}{|c}{ Non-toxic } \\
\cline { 2 - 5 } \cline { 3 - 5 } & $\begin{array}{c}\text { Total } \\
\text { number } \\
\text { of cases }\end{array}$ & $\begin{array}{c}\text { Number } \\
\text { with large } \\
\text { hearts }\end{array}$ & $\begin{array}{c}\text { Total } \\
\text { number } \\
\text { of cases }\end{array}$ & $\begin{array}{c}\text { Number } \\
\text { with large } \\
\text { hearts }\end{array}$ \\
\hline $2 \ldots \ldots$ & 5 & 0 & 3 & 0 \\
$3 \ldots \ldots$ & 18 & 4 & 3 & 1 \\
$4 \ldots \ldots$ & 23 & 6 & 11 & 1 \\
$5 \ldots \ldots$ & 25 & 8 & 7 & 0 \\
$7 \ldots \ldots$ & 8 & 5 & 3 & 1 \\
$7 \ldots$ & 1 & 0 & 1 & 1 \\
\hline
\end{tabular}

frequency of enlargement appears to increase directly with age in the toxic patients, but there is no apparent relationship in the non-toxic group.

Fifteen (19 per cent) of 81 toxic patients showed temporary variations of 10 per cent or more in cardiac area during the period of observation. In these cases there were no significant ultimate changes in area from the first to the last measurements. These variations did not bear any relation to changes in heart rate or blood pressure. It is not certain that thyrotoxicosis influ- enced these variations in size as no adequate control observations have been made in normals.

Eight toxic patients with preserved compensation received digitalis before or after operation in moderate dosage for short periods without apparent effect on their cardiac measurements.

Nine thyrotoxic patients and one with non-toxic goiter, not included in the foregoing discussion, were in congestive heart failure when first seen. All showed increase in cardiac area, varying from 9 to 62 per cent above prediction. Their individual variations in heart size are shown in Figure 7. Seven of the nine thyrotoxic patients were

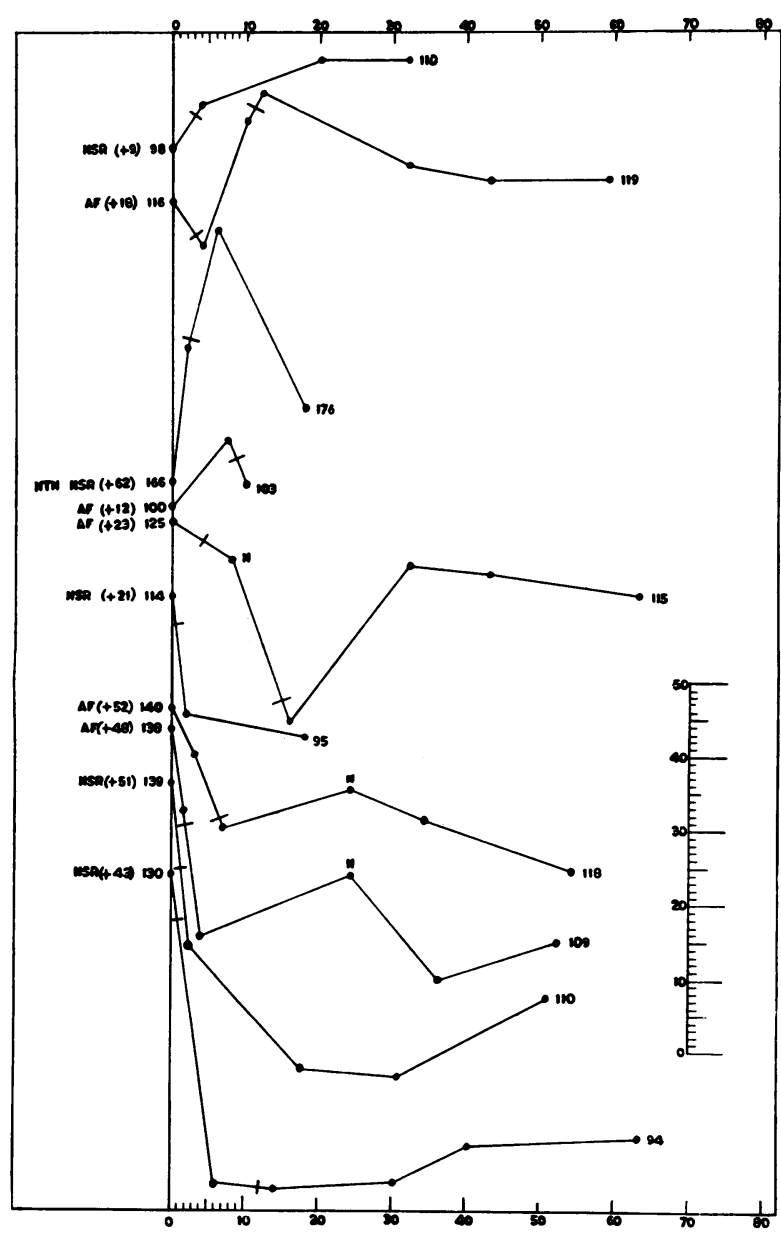

Fig. 7. Individual Variations in Cardiac Area Throughout the Period of Observation in $10 \mathrm{PA}_{\mathrm{A}}$ tients with Congestive Heart Failure Before Operation; All Were Thyrotoxic Except One (NTN) Who Had a Non-toxic, Nodular Goiter with Hypertension and Cardiovascular and Renal Disease.

$\mathrm{NSR}=$ normal sinus rhythm. $\mathrm{AF}=$ auricular fibrillation. $\mathrm{N}=$ the first measurement after re-establishment of normal sinus rhythm. 
relieved of their thyrotoxicosis after operation. Five were in auricular fibrillation; in 3 normal rhythm returned postoperatively. In 6 the cardiac area diminished after operation, despite gain of weight in 5 . One patient was followed for only a few days after operation, and her fate is unknown. The one patient known not to have been completely relieved of thyrotoxicosis showed a slight increase in cardiac area 11 months after operation. Eight of the nine toxic patients were relieved of their decompensation (including the one who remained thyrotoxic). The one nontoxic patient (a male) had cardiovascular-renal disease with hypertension and heart failure; he was unimproved four and a half months after operation.

\section{Tracheal stenosis}

The consensus in the literature is that tracheal stenosis from thyroid pressure has no demonstrable effect on the size of the heart. Parkinson and Cookson (11), in postmortem examinations of 43 thyrotoxic patients, found cardiac hypertrophy in 22 , but only 2 of these showed tracheal stenosis. We made no systematic attempt to analyze the incidence or degree of severity of tracheal stenosis. We have, however, observed a number of patients with substernal goiter causing pressure symptoms, in whom there was no cardiac enlargement.

\section{Pulmonary artery}

Bauer and Helm (24) first called attention, in patients with thyroid disease, to the prominence and increased pulsation of the pulmonary artery and pointed out that increased prominence and increased pulsation are not always combined. Parkinson and Cookson (11) found a definite prominence of this arc in 42 (32 per cent) of 130 thyrotoxic patients. The heart was normal in size in over one third (16) of the cases with definite prominence. They confirmed the presence of dilatation of the pulmonary artery by postmortem examination and pointed out that it may be obscured during life by the position of the heart. They attributed the dilatation to the widened pulse pressure and increased heart rate in thyrotoxicosis. Menard and Hurxthal (12) found a prominent (straight or convex) pulmonary arc in 52 (45 per cent) of their 115 toxic patients. They further report the same finding in 30 per cent of their patients with non-toxic goiter and in 32 per cent of non-goitrous individuals but think the prominence is greater in thyrotoxicosis. They observed a definte reduction after thyroidectomy or after disappearance of heart failure in 19 (37 per cent) of their toxic patients.

In our series of 81 thyrotoxic patients, 44 (54 per cent) showed prominence and/or increased pulsation of the pulmonary artery (Figure 1). Of these, 35 showed prominence and increased pulsation combined. Four showed prominence alone, and 5 increased pulsation alone. Of the 28 patients with non-toxic goiter, 4 (14 per cent) showed one or the other of these pulmonary artery changes. This group included one patient with slight prominence of the artery, in whom a diagnosis of chronic thyroiditis was made. Another patient showed slight dilatation of the pulmonary artery in the right anterior oblique position but not anteroposteriorly. Two patients showed increased pulsation without prominence of the artery.

In 34 of the 44 toxic patients, the abnormality of the pulmonary artery disappeared in from 1 to 7 months after operation (average 2.3 months). In this group, 16 hearts became smaller, 12 became larger, and 6 did not change in size. In the 10 patients in whom the changes persisted, 8 were classed as successful results, one was unsuccessful, and one was not followed long enough to be classified. Of these 9 patients followed, the cardiac area decreased in 2 and was unchanged in 7 . In 3 of the 4 non-toxic patients, the changes in the pulmonary artery disappeared in 1,4 and 12 months respectively without significant change in heart size. In the fourth case there was no change one year after thyroidectomy.

Seven patients with other complicating conditions showed abnormalities of the pulmonary artery before operation. Three were in decompensation; the others had aortic insufficiency, mitral insufficiency, mitral stenosis and hypertension, respectively. The abnormality disappeared after operation in all but the two patients with mitral lesions.

We were unable to demonstrate any relationship between the occurrence of changes in the pulmonary artery and $(a)$ changes in heart size, $(b)$ systemic blood pressure, (c) preoperative heart 
rate, or $(d)$ basal metabolism, in either the toxic or non-toxic group. The relative importance of alterations in pressure within the pulmonary circulation in this connection cannot be determined at present.

\section{Cardiac pulsation}

Kraus (1) first called attention to the marked change in heart size during contraction in hyperthyroidism. Bauer and Helm (24) noted the increased pulsation of the whole left border. Rösler (25) believes that the pulsation is characteristic in that the systolic contraction is quicker than in a normal heart beating at the same rate; that the contraction is not wave-like as in normals, but the whole ventricle seems to contract at the same time. Our own fluoroscopic observations supported by roentgen-kymographic studies $(27,28)$ of the pulmonary artery and left ventricular pulsations (Figure 8), confirm the presence of the characteristic pulsation in hyperthyroidism. This characteristic pulsation disappears after relief of hyperthyroidism.

\section{Cardiac shape}

The following characteristics of the cardiac configuration in hyperthyroidism have been described : prominence of the middle left border (pulmonary artery) $(9,11,24,25,26)$; prominence and increased width of the superior vena cava $(11,25)$; high aortic knob (24); rounded apex (24); a mitral configuration (9); a ham-like contour (11) ; cardiac shape and pulsation may, at times, first draw the attention of the clinician to the existence of thyrotoxicosis $(9,25)$. The lung fields may be unusually clear $(25,26)$.

We found that, at times, the anteroposterior cardiac silhouette partially simulates the "mitral configuration," because of the filling out of the normally concave middle left border by the dilated pulmonary artery; the clouded lung fields and posterior enlargement of the left auricle seen in mitral stenosis are not present in hyperthyroidism. Furthermore, the aortic knob and its pulsation are not usually as obscure as in the case of mitral stenosis. The height of the aortic knob was not significantly different from that seen in a group of non-goitrous patients of corresponding age distribution (25). We did not find increased width of the superior vena cava (12) (middle right border), but the extreme upper right vascular border was frequently somewhat oblique, probably due to right lateral displacement of the right innominate vein by the enlarged thyroid gland. We found nothing characteristic in the shape of the heart itself, exclusive of the vascular pedicle. When the heart was enlarged, the configuration suggested bilateral increase with probably slight left ventricular preponderance in most cases.

\section{SUM MARY}

Orthodiagraphic studies have been made in 102 thyrotoxic patients and 35 patients with non-toxic goiter. These studies were made before partial or subtotal thyroidectomy and at successive intervals thereafter up to one year in most instances. Our findings have been analyzed with respect to the following: (1) the incidence of abnormalities of cardiac area before operation; (2) changes in cardiac area following complete and incomplete surgical relief ; (3) the relation between changes in cardiac area and (a) duration of goiter or thyrotoxicosis, (b) postoperative weight changes, (c) postoperative hypothyroidism, (d) age, (e) sex, (f) heart failure; (4) the incidence of changes in the appearance of the pulmonary artery, and the effect of thyroidectomy on these changes; and (5) the shape and character of pulsation of the heart in hyperthyroidism.

\section{CONCLUSIONS}

1. Significant increase in cardiac area occurs frequently in uncomplicated hyperthyroidism (26 per cent of our cases). The incidence of such increase in patients with uncomplicated non-toxic goiter is also probably abnormal (14 per cent in our series of 28 cases).

2. Following thyroidectomy in uncomplicated hyperthyroidism, there is a tendency for hearts of abnormal size, whether large or small, to return toward normal and for hearts within the normal zone to remain so. This tendency is not materially affected by failure to control completely the hyperthyroidism.

3. Significant changes in cardiac area do not occur following thyroidectomy for uncomplicated non-toxic goiter.

4. Postoperative hypothyroidism may occasionally be a factor in increasing cardiac area. 

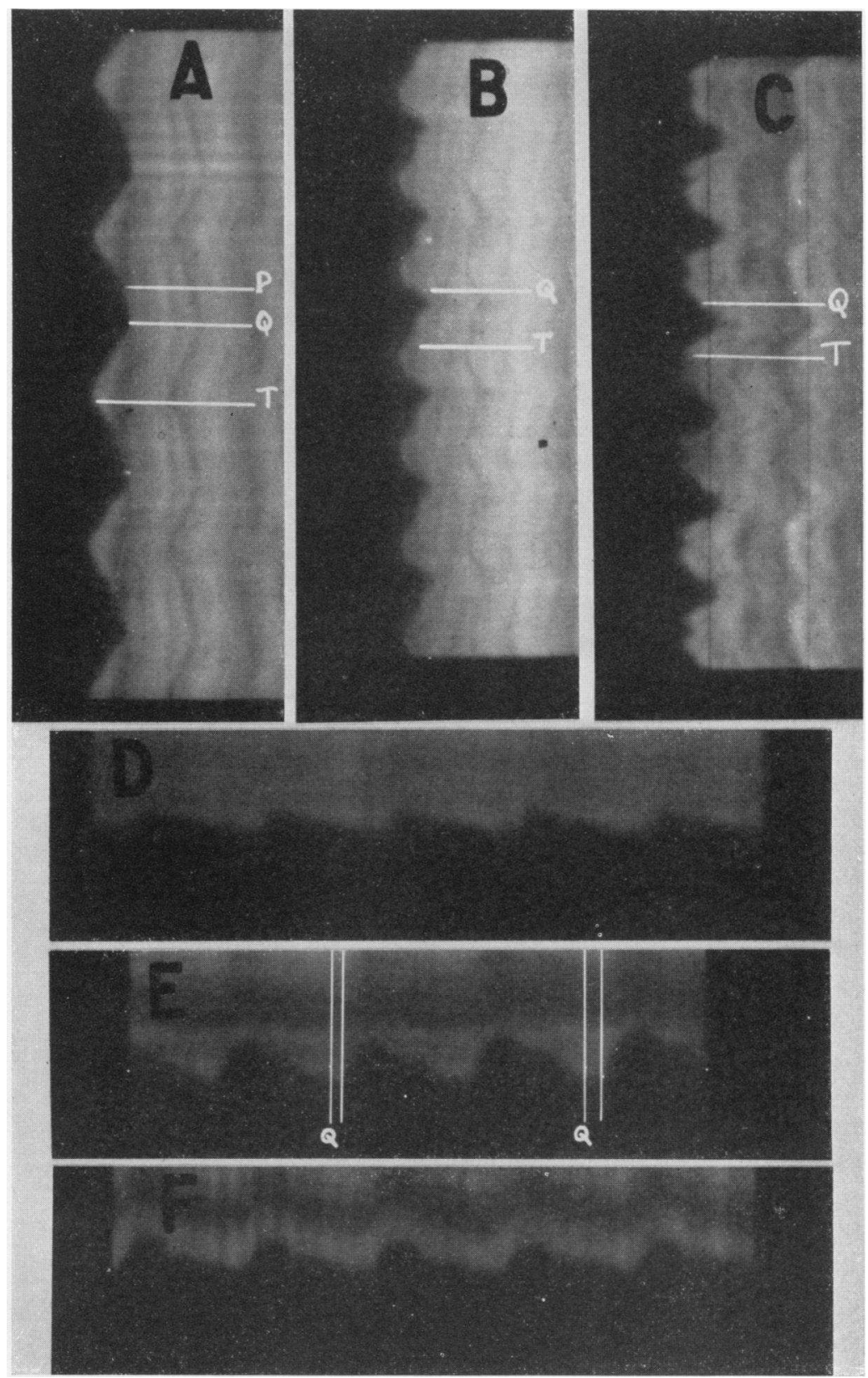

Fig. 8. Roentgen-Kymograms of the Borders of the Left Ventricle and Pulmonary Artery.

The lung fields show as the lighter zones; the heart and pulmonary artery respectively produce the black zones; the serrated edges represent the cardiac and vascular pulsations. The ventricular tracings $(A, B$ and $C)$ should be read from above downward; systole is represented by the deflection of the heart border to the left, diastole by the deflection to the right. The arterial tracings $(D, E$ and $F)$ should be read from left to right; systole is represented by the upward deflection of the vascular shadow, as in the usual pulse tracing. The letter $\mathrm{P}$ identifies the position of the beginning of the $\mathrm{P}$ wave in the simultaneously recorded electrocardiogram; $\mathrm{Q}$, the beginning of the $\mathrm{QRS}$ complex; $T$, the end of the $T$ wave $(27,28)$.

$A$. Pulsation of the left ventricular border in a normal heart, rate 110.

$B$. Pulsation of the left ventricular border in a normal heart, rate 140 .

$C$. Pulsation of the left ventricular border in a thyrotoxic heart, rate 136 . The systolic contraction is quicker and greater in extent than in the normal heart beating at approximately the same rate.

$D$. Pulsation of the pulmonary artery in a normal patient, heart rate 115 .

$E$. Pulsation of the pulmonary artery in a thyrotoxic patient, heart rate 150 (faster moving casette).

$F$. Pulsation of the pulmonary artery in a thyrotoxic patient, heart rate 110 . The amplitude of the arterial pulsation is greater in the thyrotoxic patients. 
5. Temporary variations in cardiac area, without significant ultimate changes, occur after thyroidectomy for uncomplicated hyperthyroidism in some cases (19 per cent in our series). The cause of these variations is not known.

6. Congestive heart failure in hyperthyroidism is almost always accompanied by enlargement of the cardiac area. This tends to decrease with postoperative restoration of compensation, provided the thyrotoxicosis is also relieved.

7. Increased prominence and/or pulsation of the pulmonary artery is frequent in hyperthyroidism ( 54 per cent of our cases). It occurs less frequently in association with non-toxic goiter (14 per cent of our cases). The cause of these changes is unknown. We were unable to demonstrate any relation between them and $(a)$ changes in heart size, (b) systemic blood pressure, $(c)$ preoperative heart rate, or $(d)$ basal metabolism, in patients with toxic or non-toxic goiter. In about three-fourths of our cases, the abnormality of the pulmonary artery disappeared within 1 to 7 months after thyroidectomy.

8. Cardiac pulsation, as observed fluoroscopically, is usually characteristically altered in hyperthyroidism.

9. The heart (exclusive of the vascular pedicle) does not assume a characteristic shape in persons with toxic or non-toxic goiter.

\section{BIBLIOGRAPHY}

1. Kraus, F., Ueber das Kropfherz. Wien. klin. Wchnschr., 1899, 12, 416.

2. Kraus, F., Ueber Kropfherz. Deutsche med. Wchnschr., 1906, 32, 1889.

3. Blauel, Muller, O., and Schlayer, Ueber das Verhalten des Herzens bei Struma. Beitr. z. klin. Chir., 1909, $62,119$.

4. Steiner, O., Beziehungen zwischen Kropf und Herz, Ihr Verhalten nach der Strumektomie. Mitt. a. d. Grenzgeb. d. Med. u. Chir., 1922, 35, 39.

5. Willius, F. A., and Boothby, W. M., The heart in? exophthalmic goiter and adenoma with hyperthyroidism. M. Clin. North America, 1923, 7, 189.

6. Coller, F. A., The morbidity of endemic goiter. J. A. M. A., 1924, 82, 1745.

7. Kerr, W. J., and Hensel, G. C., Observations of the cardiovascular system in thyroid disease. Arch. Int. Med., 1923, 31, 398.

8. Meyer, A. W., and Sulger, E., Das Kropfherz vor und nach der Operation. Med. Klin., 1926, 22, 838.

9. Meyer-Borstel, H., Über Form- und Grössenveränderungen des Herzens bei Struma. Fortschr. a. d. Geb. d. Röntgenstrahlen, 1930, 41, 695.
10. Hurxthal, L. M., Menard, O. J., and Bogen, M. E., The size of the heart in goiter. A teleoroentgenographic study, A. J. M. Sc., 1930, 180, 772.

11. Parkinson, J., and Cookson, H., The size and shape of the heart in goiter. Quart. J. Med., 1931, 24, 499.

12. Menard, O. J., and Hurxthal, L. M., Changes observed in the heart shadow in toxic goiter before and after treatment. Ann. Int. Med., 1933, 6, 1634.

13. Hurxthal, L. M., Discussion in Transactions Amer. Heart Assoc., Am. Heart J., 1932, 8, 152.

14. Lerman, J., and Means, J. H., Cardiovascular symptomatology in exophthalmic goiter. Am. Heart J., 1932, 8, 55.

15. Jones, N. W., Seabrook, D. B., and Menne, F. R., A clinical study of goiter in the Pacific Northwest, with special reference to the state of the heart. Am. Heart J., 1932, 8, 41.

16. Burnett, C. T., and Durbin, E., The signs and symptoms of heart changes in toxic goiter. Am. Heart J., 1932, 8, 29.

17. Kepler, E. J., Hypertrophy of the heart and congestive heart failure in hyperthyroidism: A clinical and pathologic study of 178 fatal cases. Proc. Staff Meet., Mayo Clin., 1932, 7, 397.

18. Simonds, J. P., and Brandes, W. W., The size of the heart in experimental hyperthyroidism. Arch. Int. Med., 1930, 45, 503.

19. Hodges, F. J., Heart; x-ray examination. Wisconsin M. J., 1929, 28, 46.

20. Margolies, A., X-ray of the heart and great vessels. Cyclopedia of Medicine, F. A. Davis Co., Philadelphia, 1932, 3, 424.

21. Hodges, P. C., and Eyster, J. A. E., Estimation of cardiac area in man. Am. J. Roentgenol., 1924, $12,252$.

22. Hodges, F. J., and Eyster, J. A. E., Estimation of transverse cardiac diameter in man. Arch. Int. Med., 1926, 37, 707.

23. Roesler, H., The relation of the shape of the heart to the shape of the chest. Am. J. Roentgenol., 1934, 32, 464.

24. Bauer, J., and Helm, F., Über Röntgenbefunde bei Kropfherzen. Deutsches Arch. f. klin. Med., 1912, 109, 73.

25. Rösler, H., Das Röntgenbild des Herzen beim Hyperthyreoidismus. Wien. Arch. f. inn. Med., 1928, 15, 539.

26. Pollitzer, H., Ueber Volumen pulmonis diminutum als Symptom des Morbus Basedowii. Wien klin. Wchnschr., 1924, 37, 735.

27. Margolies, A., and Wolferth, C. C., The opening snap (Claquement d'ouverture de la mitrale) in mitral stenosis, its characteristics, mechanism of production and diagnostic importance. Am. Heart J., 1932, 7, 443.

28. Wolferth, C. C., and Margolies, A., Asynchronism in contraction of the ventricles in the so-called common type of bundle branch block. Am. Heart J., 1935, 10, 425. 